\title{
The measurement of collaborative culture in secondary schools: An informal subgroup approach
}

\author{
Chloé Meredith $^{\mathrm{a}^{*}}$, Nienke M. Moolenaar ${ }^{\mathrm{b}}$, Charlotte Struyve ${ }^{\mathrm{a}}$, Machteld \\ Vandecandelaere ${ }^{a}$, Sarah Gielen ${ }^{\text {a }}$ \& Eva Kyndt ${ }^{\text {a }}$ \\ ${ }^{a}$ KU Leuven, Belgium \\ ${ }^{\mathbf{b}}$ Utrecht University, The Netherlands
}

Article received 28 November / revised 17 January / accepted 21 January / available online 28 March

\begin{abstract}
Research on teacher collaboration underlines the importance of a collaborative culture for teachers' functioning. However, while scholars usually regard collaborative culture as a school team characteristic, this study argues that subgroups may be more meaningful units of analysis to conceptualize and assess teachers' perceptions of collaborative culture. Based on the assumption that collaborative culture is developed, expressed, and maintained in frequent work-related interactions, this study hypothesizes that collaborative culture is not homogenously spread over the school but rather varies between informal subgroups. Data from 760 Flemish teachers were examined using social network analysis and consensus analyses. The results provided evidence that perceptions on collaborative culture are more homogeneous within informal subgroups that are characterized by frequent interactions than the entire school team. This finding stresses the importance of assessing the meaningful unit of analysis for collective-level and socially-constructed concepts, such as collaborative culture. Moreover, the benefits and potential of a social network approach to identify (socially stable) subunits within the school team are illustrated.
\end{abstract}

Keywords: Collaborative culture, Informal subgroups, Social network analysis, Secondary Schools

\footnotetext{
* Corresponding author: Chloé Meredith, Faculty of Psychology and Educational Sciences, KU Leuven. Dekenstraat 2 bus 3772, 3000 Leuven, Belgium. chloe.meredith@kuleuven.be DOI: http://dx.doi.org/10.14786/flr.v5i2.283
} 


\section{Introduction}

Several studies have described the benefits of having a collaborative culture in schools. As a result, teachers have repeatedly been advised to move away from traditional norms of isolation and individuality and move towards greater collaboration (Louis \& Kruse, 1995; Marks \& Louis, 1997). Teachers are encouraged to discuss problems, offer different viewpoints, leading to constructive collaboration and consensus (Barczak, Lassk, \& Mulki, 2010). In line with research in various organizations, Hargreaves (1994) and Leithwood, Leonard, and Sharatt (1998) indicated that cultures with characteristics expressed in terms of collegiality and collaboration generally are those types that promote feelings of professional involvement, efficacy and satisfaction.

Collaborative culture can be regarded as a part of the organizational culture (Peterson \& Beard, 2004, Sveiby \& Simons, 2002). Organizational culture has been described as the shared, and often taken for granted, values, norms and practices within an organization (Schein, 2010). In previous studies, collaborative culture has often been conceptualized and assessed as a characteristic of the entire organization, in this case the school (e.g., Strahan, 2003; Waldron \& McLeskey, 2010). However, questions can be asked whether the school is always the most meaningful unit to conceptualize and assess collaborative culture. A precondition for and significant characteristic of organizational culture is that values, norms and practices are shared by a significant portion of organizational members (Yang, 2007). These shared values, norms, and practices are developed, expressed and maintained in the frequent communication of organizational members (Dumay, 2009). However, within a school, especially in larger schools, interactions are often concentrated in subgroups (Firestone \& Pennell, 1993; Frank, 1995). As a result, subgroup members may develop their own norms, values and practices concerning collaboration, resulting in subcultures within the school (Soeters, 1988). If we want to investigate collaborative culture as a working condition that affects teachers, it is crucial to identify the relevant unit of analysis. In order to make correct inferences, this unit of analysis needs to reflect the actual collaborative culture one works in. This study therefore focuses on the conceptualization and assessment of collaborative culture and investigates whether subgroups are more meaningful units of analysis than the entire school team. As culture is assumed to result from frequent work-related interactions among teachers, subgroups are identified by means of social network analysis. In this way, this study not only contributes to the assessment of socially-constructed concepts, such as collaborative culture, but also offers a different, innovative perspective on the identification of (socially stable) subunits within the school.

\section{Conceptual framework}

\subsection{Conceptualizing collaborative culture}

Collaborative culture can be defined as the shared values, norms and practices on the matter of teamwork and communication. Flores (2004) referred to collaborative cultures in schools as the working relationships, which are spontaneous, voluntary, evolutionary, and development-oriented, wherein the stance of working together becomes part of the personality of the school. Collaboration can then be regarded as a process in which teachers come together to discuss, share knowledge, coach each other, reflect on common experiences and build the curriculum together (Lieberman, 1990, 1995). By doing this, teachers create a culture of acceptance for mutual support and collaboration (Louis, Marks, \& Kruse, 1996), wherein a norm of collegiality becomes a part of the working stance (Little, 1982; Nias, 2005).

This 'sharedness', or homogeneity, of values, norms, and practices is developed, expressed, and performed in the day-to-day interactions of individuals working in the same context, facing the same challenges and goals (Dumay, 2009; Harris, 1994; Van Maanen \& Schein, 1979). However, in most schools, frequent interactions with all school team members are practically impossible and as a result, culture is 


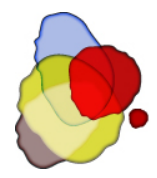

dispersed over different parts (Sackmann, 1992). This dispersion within an organization does not necessarily imply that a culture is heterogeneous, but rather that there are subgroups who have their own culture (Adkins \& Caldwell, 2004). Previous studies already provided evidence that members of subgroups share beliefs and values, and exhibit similar actions based on these beliefs and values (Ashforth \& Mael, 1989; Harris, 1994). Moreover, social psychologists and sociologists indicated that individuals perceive and evaluate their organization based on what happens in their close social neighborhood, meaning the people with whom they engage in frequent interactions (Lock \& Crawford, 1999; Sackmann, 1992). This is important, especially because culture is manifested in and often measured by the perceptions of individuals (Hofstede, 1998). In other words, teachers that frequently interact, will not only develop and maintain shared values, norms and practices concerning collaboration, they will also perceive and evaluate collaboration in the school based on what happens in their social neighborhood. Previous studies have already indicated that subgroups can be found within the school team (Frank, 1996). Frank (1995) argued that subgroups can be regarded as the crucial link between individuals and organizations, and may therefore be more meaningful units to conceptualize and measure collaborative culture.

\subsection{Assessing collaborative culture: An informal subgroup approach}

Previous studies often focused on formal subgroups to determine the boundaries of subunits within the school (e.g., Busher \& Blease, 2000; Visscher \& Witziers, 2004). This approach is based on the assumption that interactions among teachers follow the boundaries of this formal structure. However, along with the recent rise of interest in social networks in organizations, studies have started focusing on informal subgroups that are characterized by actual social interactions, and do not necessarily follow the same constellations as their formal counterparts (Frank, Penuel, \& Krause, 2015). However, based on the assumption that culture is constructed and evaluated in frequent work-related interactions, it is crucial to identify subgroups that are characterized by frequent interactions. Therefore, this study adopts an informal subgroup approach in order to conceptualize and measure collaborative culture. An informal subgroup approach takes the work-related social network of members into account to subdivide the school in subgroups (Frank, 1995, 1996). As a result, these informal subgroups can be regarded as stable social units within the broader organization (Frank \& Yasumoto, 1998). We therefor expect that these subgroups may be more meaningful units of analysis to assess collaborative culture, in comparison to the whole school team. To empirically substantiate this assumption, the following research hypothesis is tested:

Perceptions of collaborative culture are more homogenous within informal subgroups compared to on the entire school team's aggregated perception on collaborative culture.

\section{Method}

\subsection{Participants}

Data for this study were collected in secondary schools in Flanders (northern part of Belgium with approximately 6.500.000 inhabitants), using an online survey. The "school team questionnaire" was part of the LiSO-project (Dutch acronym for Student Careers in Secondary Education) and was administered in 20 secondary school teams. In this study, a 'school team' consisted out of all teachers who actually worked in the same secondary school campus (= in the same geographical unit). All teachers of the 20 secondary schools received an invitation to fill out the online questionnaire that addressed the working conditions in the school. However, we could only include secondary schools that had a response rate of at least $75 \%$, which is the threshold to reliably identify informal subgroups using social network analysis (Borgatti, Carley, \& Krackhardt, 2006; Kossinets, 2006). In 13 schools, a response rate of $75 \%$ or more was reached, resulting in 


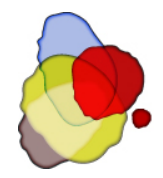

a dataset of 760 teachers. Respondents in our dataset were on average around 40.65 years old $(\mathrm{SD}=10.62)$, had 11.65 years of experience $(\mathrm{SD}=9.68)$ in their current school and $64 \%$ of them were female.

\subsection{Instrument and analytic strategy}

\subsubsection{Determining informal subgroups}

In order to determine informal subgroups within the secondary school, we included a sociometric question in the survey. As we wanted to grasp the day-to-day work-related interactions of teachers, we decided to focus on the information network and asked the following question: "Whom do you go to for class-related information? (For instance, for teaching materials and methods, learning, content and classroom management)". A roster with all teachers' names was presented and participants could indicate to whom of their colleagues they went to and on what frequency basis (presented in 8 categories going from 'once a year' to 'daily'). Teachers could indicate an unlimited number of colleagues.

In order to identify informal subgroups, we used a social network approach. Social network analysis makes it possible to investigate the patterns of interactions between actors (Scott, 1991). It focuses on a set of individuals and the relationships connecting them (Wasserman \& Faust, 1994). Several authors indicated that social network analysis helps to unravel social phenomena that can partly be explained by social structure (e.g., Wellman \& Frank, 2001). Based on the patterns and frequency of work-related interactions, informal subgroups can be identified. In this study, the approach of Frank (1996) was used to determine nonoverlapping cohesive subgroups. A non-overlapping approach, meaning that teachers could only be member of one subgroup, was selected, as an overlapping approach makes it difficult to establish "an inside and an outside" of a social unit (Abbott, 1995, p. 872). In order to identify these non-overlapping cohesive subgroups, the Kliquefinder software was used (Frank, 1996). The procedure implemented in Kliquefinder is based on the Exponential Random Graph Model (ERGM) framework. The algorithm within this software identifies subgroups by iteratively reassigning actors in order to see if the probability that two actors interact increases if they are members of the same subgroup. Actors are assigned to a cohesive subgroup once the maximum probability of having a tie with other subgroup members is reached (for more information about the software and algorithm, see Frank, 1995).

\subsubsection{Evaluating homogeneity of collaborative culture}

In order to test the hypothesis that perceptions on collaborative culture are more homogenous within the informal subgroup than within the entire school team, we included a scale to assess collaborative culture. Schein (1985) indicated that actual practices are the most visible and tangible aspects of organizational culture, and underlying assumptions, values and norms come to surface in these practices. We selected six items of the scale of Leonard (2002) addressing the perceptions of teachers on collaborative culture. We only included the items that addressed the actual collaboration within the school, such as 'In my school, teacher collaboration is strong' and 'In my school, teaching is a team activity, rather than an individual activity'. The Cronbach's Alpha of this subscale was satisfactory $(\alpha=.85)$. Based on a confirmatory factor analysis, the fit of the scale was found acceptable $(\mathrm{CFI}=.954, \mathrm{TLI}=.968, \mathrm{SRMR}=.042, \mathrm{RMSEA}=.04)$.

Homogeneity of perceptions was operationalized by combining two complementary approaches to assess within-group agreement, namely 1) a consensus-based approach, using the intraclass correlation coefficient $\left(\mathrm{ICC}_{(1)}\right)$ as a measure of homogeneity; and 2) a disconsensus-based approach, calculating the average deviation index $\left(\mathrm{AD}_{\mathrm{Mj}}\right)$ as a measure of lack of homogeneity. At the same time, these measures give information on the aggregation of individual perceptions to the proposed level of analysis (Raudenbush \& Bryk, 2002). 
a) A consensus-based approach to homogeneity of perceptions.

First, we assessed the $\mathrm{ICC}_{(1)}$. This $\mathrm{ICC}_{(1)}$ reflects the agreement between any pair of individuals within the same group (McGraw \& Wong, 1996). The outcome is the portion of total variance in a variable that can be explained by membership in a group (Raudenbush \& Bryk, 2002). In other words, a low ICC $_{(1)}$ indicates that only a small proportion of the variance can be explained by membership of the informal subgroup, and variance within the subgroup is high. The $\mathrm{ICC}_{(1)}$ is interpreted as an effect size with values of $.01, .10$ and .25 respectively indicating a small, median and large effect (Bliese, 2000; Raudenbush \& Bryk, 2002). The advantage of using the $\mathrm{ICC}_{(1)}$ to reflect subgroup homogeneity of perceptions is that it corrects for group size and provides group-level properties that are not biased by either group size or the number of groups in the sample (Bliese, 2000).

b) A disconsensus-based approach to homogeneity of perceptions.

$\mathrm{AD}_{\mathrm{Mj}}$ is the degree of within-group disconsensus. It reflects the within-group variability, so high $\mathrm{AD}_{\mathrm{Mj}}$ scores indicate within-group dispersion. The calculation of it consists out of two steps. First the average deviation for each scale item (j) is computed. Second, the average deviation for the six items of the scale is calculated. This measure provides an alternative for the highly criticized within-group agreement $\left(\mathrm{r}_{\mathrm{wg}}\right)$ of James, Demaree, and Wolf (1984), because it does not require an a priori specification of a null response range and it takes the metric of the original response scale into account (González-Romá, Peiró, \& Tordera, 2002).

Both measures were calculated for informal subgroups and school teams to compare the homogeneity of perceptions on collaborative culture in subgroups and schools. These measures reflect to what extent teachers perceive collaborative culture in a similar/dissimilar way. A high degree of correspondence is needed to draw inferences about organizational working conditions, such as culture, and to aggregate perceptual scores to the level of the organization or organizational unit (James \& Jones, 1974; Schneider, 1975). Aggregation is interesting because, and only justified when, the mean score goes beyond individual perceptions, and reflects an actual organizational condition (Payne, Fineman, \& Wall, 1976). In other words, in order to investigate collaborative culture as a characteristic of the organization or organizational subgroup, perceptions need to reflect sufficient agreement.

\section{Results}

\subsection{The identification of informal subgroups}

Based on the analyses in Kliquefinder, the 13 schools were found to be consisting of 136 informal subgroups. On average, there were 11.33 subgroups within a school team $(\operatorname{Min}=5, \operatorname{Max}=25, S D=6.15)$, containing an average of 6.31 members $(S D=1.99)$. Within these subgroups, the average age was 40.67 years $(S D=6.13)$, average experience was 11.78 years $(S D=5.36)$, and averagely $62.35 \%(S D=.33)$ of the subgroup members were female. For all schools, cluster p-values were below .01, indicating that teachers were significantly more likely to interact frequently with colleagues that were part of the same identified subgroup.

\subsection{Cultural consensus within schools and informal subgroups}

The results of homogeneity of collaborative culture indicated that the intraclass correlation for the subgroup level $\left(\mathrm{ICC}_{(1)}=.21\right)$ is almost twice as high as for the school level $\left(\mathrm{ICC}_{(1)}=.11\right)$, reflecting lower variance within the informal subgroup than within the school team. This means that agreement is higher 


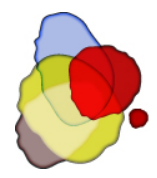

within the informal subgroup. Within-group disconsensus results showed that within-group dispersion was lower on the subgroup level $\left(\mathrm{AD}_{\mathrm{Mj}}=.66\right)$ in comparison to the school team level $\left(\mathrm{AD}_{\mathrm{Mj}}=.77\right)$. These results provide support for our research hypothesis, namely that perceptions on collaborative culture are more homogenous within the informal subgroup in comparison to the entire school team. In other words, the perceptions on collaborative culture are more similar among teachers within the same informal subgroup compared to teachers the same school, even when correcting for group size. As a high degree of correspondence is necessary to make inferences about organizational features, the informal subgroup seems a more appropriate unit to conceptualize and assess collaborative culture.

\section{Discussion}

Over the last decades, the importance of a collaborative culture within organizations, such as secondary schools, has been advocated by several researchers. In many cases, collaborative culture is regarded as a school feature, with the whole school team being the meaningful unit of analysis. However, based on the assumption that culture is developed, maintained and evaluated in the day-to-day communication among organizational members, this study hypothesized that the subgroup might be a more meaningful unit of analysis for both the conceptualization and measurement of collaborative culture. To test this hypothesis, a social network approach was adopted to identify stable social units that are characterized by frequent work-related interactions among their members. Thereafter, we compared the homogeneity of perceptions of collaborative culture in these informal subgroups and the entire school team. In what follows, several theoretical and methodological implications are discussed and limitations and suggestions for future research are indicated.

\subsection{Theoretical and methodological implications}

\subsubsection{Collaborative culture as an informal subgroup characteristic}

The main goal of this study was to address the conceptualization and measurement of collaborative culture in secondary schools. Our findings indicated that the perceptions on the school's collaborative culture are more homogenous within the informal subgroup than the entire school team. In other words, members of an informal subgroup evaluate collaborative culture more similarly than all members of the entire school team. Linking these findings to the conceptual framework, two important, interrelated conclusions can be drawn. First, the fact that there is more homogeneity within subgroups suggests that there are, to some extent, collaborative subcultures within secondary school teams. Second, our findings provide evidence for earlier conclusions that teachers perceive and evaluate the organization based on what happens in their close social neighborhood (Van Maele, Moolenaar, \& Daly, 2015). Based on this, it can be concluded that informal subgroups are more meaningful units of analysis to conceptualize and assess collaborative culture, in comparison to the entire school team. In secondary schools, it is often impossible to communicate, and consequently collaborate, with all other school team members. This conclusion stresses the importance of identifying the appropriate level of assessment, especially for socially-constructed concepts.

This conclusion is not solely relevant for the concept of collaborative culture and the context of secondary schools. The finding that culture is indeed developed, maintained and evaluated in informal subgroups, characterized by frequent interactions, could also be relevant for other collective-level concepts, such as other types of organizational culture, collective efficacy or organizational trust. Moreover, the reasoning behind the importance of (informal) subgroups might also applicable in other organizations. Research in organizations should therefore be aware that collective-level concepts are, to some extent, 
socially constructed and, as a result, differ between subgroups within the organization. In line with Frank (1995), we argue that subgroups can be regarded as the crucial link between individuals and organizations.

\subsubsection{Using social network analysis to identify informal subgroups}

In order to identify subgroups, this study adopted a social network approach. This approach made it possible to identify subgroups that are characterized by frequent informal work-related interactions, and can therefore be considered as stable social units (Frank \& Zhao, 2005). While previous studies relied on the boundaries of formal structure (e.g., departments or teams) to identify subgroups (e.g., Ball \& Lacy, 1984; Hargreaves \& Hargreaves, 2006; Siskin, 1991), this study used the work-related information seeking network of teachers. This approach has not only the advantage that it captures meaningful subunits that are characterized by actual interactions. It provides the possibility to apply a uniform approach for all schools in the sample, even if they differ in formal structure or the meaning that is given to it. For instance, two of the schools in our sample indicated that they did not have the usual 'subject department structure'. Four schools indicated that next to subject department structure, they had other formal subunits, such as grade-level teams or working groups. Finally, three schools mentioned that the subject department structure was a purely formal constellation that did not reflect the actual interactions and subunits within the school. A social network approach helps to overcome the issues of identifying the (most) meaningful subunit.

The interest in social networks has increased exponentially during the last three decades (Lazega \& Snijders, 2016). Based on the assumption that 'relationships matter', several researchers already gained thorough understanding of the structure and content of teachers' professional relationships (e.g., Coburn \& Russel, 2008; Daly, Moolenaar, Bolivar, \& Burke, 2010; Moolenaar, Sleegers, \& Daly, 2012). This study provided further insight into the social structure of secondary schools and contributed to the understanding on how social-structural and cultural aspects of secondary schools are intertwined. Moreover, the results showed that research focusing on the school team features benefits from a social network approach, as it provides the possibility to identify stable social units within the broader organization.

\subsection{Limitations and suggestions for future research}

First, several limitations can be formulated on the identification of informal subgroups. Based on theoretical ideas and empirical findings, this study adopted an informal subgroup approach to conceptualize and measure collaborative culture. To identify our informal subgroups, data on the information seeking network of teachers were used. The selection of the criterion 'seeking information' was based on the reasoning that interactions that are characterized by 'seeking work-related information' are one of the most general work-related interactions. As we were interested in subgroups that were characterized by day-to-day work-related interactions, this criterion seemed to fit our purpose best. In advance, we checked whether this criterion did not already reflect collaborative culture itself and calculated the correlation between subgroup density, namely the extent to which subgroups members are connected by information ties, and perceptions on collaborative culture in the subgroup. Our results showed that both measures were not significantly related $(\mathrm{r}=.13, \mathrm{p}>.05)$. This indicated that subgroups with more information seeking interactions are not necessarily perceived as having a higher collaborative culture. In other words, the criterion of 'seeking information' (and the determination of subgroups) is not related to the perception of collaborative culture itself. It seems that more profound interactions are necessary to establish and measure collaborative by means of interactions. Future research could include different types of work-related interactions to further look into the identification of informal subgroups and the measurement of collaborative culture by means of social networks. Also, to identify our informal subgroups; the non-overlapping cohesive subgroup approach of Frank $(1995,1996)$ was adopted. We chose this approach as it has been applied and validated in a wide array of network studies (e.g., Foster-Fishman, Berkowitz, Lounsbury, Jacobson, \& Allen, 2001; Frank \& Yasumoto, 1998; McFarland, 2001). However, methodologists have developed and employed various other 
techniques to identify cohesive subgroups based on the extent of interaction between actors (Borgatti \& Everett, 2000). Future research could explore and compare other ways of attributing members to subgroups. Finally, we treated these subgroups as autonomous entities with their own norms values and beliefs. However, future research could also address the spillover effects of interactions between subgroups, taking the larger social structure of the school into account. The inclusion of both the subgroup and school as units of analysis seems promising to capture important working conditions that affect the functioning of teachers.

Second, limitations concerning the measurement of collaboration can be identified. The scale is aimed at measuring a school related concepts and the items of the scale are formulated assuming that the school is the reference group. The approach adopted in this study can be justified by the assumption that teachers' perceptions are based on what happens in their social neighborhood. However, in future research, a more accurate measurement of collaborative culture could use the, formal or informal, subgroup as reference group. This could make it possible to distinguish between school collaborative culture and subgroup collaborative culture. For instance, the research of Adkins and Caldwell (2004) made a difference between subgroup culture and the organizational culture. Moreover, as Schein (1985) indicated that actual practices are the most visible and tangible aspects of organizational culture, it would be interesting to measure collaborative culture by means of observing the actual collaborative practices that take place in the school. This would not only lead to higher response rates, but also reduce potential response biases, such as social desirability bias, which can be present in self-report instruments such as online questionnaires (Krumpal, 2013).

Third, it would be interesting to include other features of the subgroup to investigate the presence of collaborative culture. For instance, the research of Barczak, Lassk, and Mulki (2010) found that team trust impacts collaborative culture. In addition, also the consequences of collaborative culture could be further researched, as well as other types of organizational culture.

Fourth, as in most survey-based research, our data collection was characterized by incomplete data. Missing data can be a significant problem in social network analysis because, as noted, individuals are considered interdependent from social ties in their social context (Kossinets, 2006). In order to achieve high response rates in each school, several strategies were adopted to convince teachers to fill out the questionnaire. First, teachers were informed about the questionnaire by means of mails, posters and brochures. In this communication, it was emphasized that all responses would be anonymized, that each response was crucial to get more insight in teacher careers and the working conditions in schools, and that general conclusions would be fed back to policy agencies. Second, response rates were followed up and several reminders were sent out. Finally, school leaders were motivated to convince their team to fill out the questionnaire. If the school team achieved a response rate of more than $90 \%$, an anonymized feedback report was provided. As only schools with a response rate of $75 \%$ or more were included, missing data was limited. In studies adopting a classic statistical approach, and where standard sampling is used to draw a representative sample from a population, there are special techniques available to correct parameter estimates for imperfect response rates (Rubin \& Little, 2002). However, in the case of social network analysis, these kind of treatments are questionable, and although methods for dealing with such issues have been proposed, researchers agree that, at this point in time, list wise deletion is the most appropriate approach (Robins \& Alexander, 2004).

Finally, our results showed that socially constructed working conditions, more specifically collective-level concepts that are developed and sustained in collegial interactions, cannot simple be regarded as organizational-level concepts. Through interactions, members of subgroups develop and maintain shared values, norms and practices. At the same time, this social neighborhood defines how teachers perceive the school and its working conditions. Future research therefore needs to pay attention to working conditions that may potentially differ between subgroups within the school. When collective-level concepts are at stake, it is crucial to identify the meaningful level of analysis. Only in this way, correct interferences about the importance of these working conditions can be made. The main innovation of this paper is the adoption of a social network approach to identify meaningful subunits and measure collaborative 
culture. We provided an example of how social network analysis can provide more insight and methodological advancements in educational research.

\section{Keypoints}

- An informal subgroup approach was adopted to determine meaningful subunits within secondary school teams

- Informal subgroups, characterized by frequent work-related interactions, are identified by means of social network analysis

- Perceptions of collaborative culture are more homogenous within informal subgroups compared to on the entire school team's aggregated perception on collaborative culture.

- The importance of identifying the meaningful unit of analysis for collective-level and sociallyconstructed concepts is stressed

\section{Acknowledgments}

This study was conducted within the framework of the Policy Research Center on Study and School Careers and was financed by the Flemish Ministry of Education (Belgium). The conclusions of the study do not necessarily reflect the views (of (and do not commit) the financing body.

\section{References}

Abbott, A. (1995). Things of Boundaries. Social Research, 62(4), 857-882.

Adkins, B., \& Caldwell, D. (2004). Firm or subgroup culture: where does fitting in matter most? Journal of Organizational Behavior, 25(8), 969-978. doi: 10.1002/job.291

Ashforth, B. E., \& Mael, F. (1989). Social identity theory and the organization. Academy of management review, 14(1), 20-39. doi: 10.5465/AMR.1989.4278999

Ball, S. J. \& Lacy, C. (1984) Subject disciplines as the opportunity for group action: a measure critique of subject subcultures. In A. Hargreaves \& P. Woods (Eds.), Classrooms and staffrooms: the sociology of teachers and teaching (pp. 232-244). Milton Keynes, UK: Open University Press.

Barczak, G., Lassk, F., \& Mulki, J. (2010). Antecedents of team creativity: An examination of team emotional intelligence, team trust and collaborative culture. Creativity and Innovation Management, 4, 332-345. doi: $10.1111 / \mathrm{j} .1467-8691.2010 .00574 . \mathrm{x}$

Bliese, P. D. (2000). Within-group agreement, non-independence, and reliability: Implications for data aggregation and analysis. In K.J. Klein \& S.W. Kozlowski (Eds.), Multilevel theory, research, and methods in organizations (pp. 349-381). San Francisco, CA: Jossey-Bass.

Borgatti, S. P., Carley, K. M., \& Krackhardt, D. (2006). On the robustness of centrality measures under conditions of imperfect data. Social Networks, 28, 124-136. doi: 10.1016/j.socnet.2005.05.001

Borgatti, S. P., \& Everett, M. G. (2000). Models of core/periphery structures. Social networks, 21(4), 375395. doi: 10.1016/S0378-8733(99)00019-2

Busher, H., \& Blease, D. (2000). Growing collegial cultures in subject departments in secondary schools: working with science staff. School Leadership \& Management, 20(1), 99-112. doi: $10.1080 / 13632430068905$

Coburn, C. E., \& Russell, J. L. (2008). District policy and teachers' social networks. Educational Evaluation and Policy Analysis, 30, 203-235. doi: 10.3102/0162373708321829 
Cohen, S. G., \& Bailey, D. E. (1997). What makes teams work: Group effectiveness research from the shop floor to the executive suite. Journal of management, 23(3), 239-290. doi: 10.1016/S01492063(97)90034-9

Daly, A. J., Moolenaar, N. M., Bolivar, J. M., \& Burke, P. (2010). Relationships in reform: The role of teachers' social networks. Journal of Educational Administration, 48, 359-391. doi: $10.1108 / 09578231011041062$

Dumay, X. (2009). Origins and consequences of schools' organizational culture for student achievement. Educational Administration Quarterly, 45(4), 523-555. doi: 10.1177/0013161X09335873

Firestone, W. A., \& Pennell, J. R. (1993). Teacher commitment, working conditions, and differential incentive policies. Review of educational research, 63(4), 489-525. doi: 10.3102/00346543063004489

Flores, M. A. (2004). The impact of school culture and leadership on new teachers' learning in the workplace. International Journal of Leadership in Education, 7, 297-318. doi: 10.1080/1360312042000226918

Foster-Fishman, P. G., Berkowitz, S. L., Lounsbury, D. W., Jacobson, S., \& Allen, N. A. (2001). Building collaborative capacity in community coalitions: A review and integrative framework. American journal of community psychology, 29(2), 241-261. doi: 10.1023/A:1010378613583

Frank, K. A. (1995). Identifying cohesive subgroups. Social Networks, 17, 27-56. doi: 10.1016/03788733(94)00247-8

Frank, K. A. (1996). Mapping interactions within and between cohesive subgroups. Social networks, 18, $93-$ 119. doi: $10.1016 / 0378-8733(95) 00257-X$

Frank, K. A., Penuel, W. R., \& Krause, A. (2015). What Is A "Good" Social Network For Policy Implementation? The Flow Of Know-How For Organizational Change. Journal of Policy Analysis and Management, 34(2), 378-402. doi: 10.1002/pam.21817

Frank, K. A., \& Yasumoto, J. Y. (1998). Linking action to social structure within a system: Social capital within and between subgroups. American journal of sociology, 104, 642-686. doi: 10.1086/210083

Frank, K. A., \& Zhao, Y. (2005). Subgroups as meso-level entities in the social organization of schools. In L.V. Hedges \& B. Schneider (Eds.), Social Organization of Schooling. New York, NY: Sage Publications.

González-Romá, V., Peiró, J. M., \& Tordera, N. (2002). An examination of the antecedents and moderator influences of climate strength. Journal of Applied Psychology, 87(3), 465-473. doi: 10.1037//00219010.87.3.465

Hargreaves, A. (1994). Changing teachers, changing times: Teachers' work and culture in the postmodern age. New York, NY: Teachers' College Press.

Hargreaves, D. H., \& Hargreaves, D. (2006). Social relations in a secondary school. London, UK: Routledge \& Kegan Paul. doi: 10.4324/9780203001837

Harris, S. G. (1994). Organizational culture and individual sensemaking: A schema-based perspective. Organization Science, 5(3), 309-321. doi: 10.1287/orsc.5.3.309

Hofstede, G. (1998). Attitudes, values and organizational culture: Disentangling the concepts. Organization studies, 19(3), 477-493. doi: 10.1177/017084069801900305

James, L. R., Demaree, R. G., \& Wolf, G. (1984). Estimating within-group interrater reliability with and without response bias. Journal of Applied Psychology, 69(1), 85-98. doi: 10.1037/0021-9010.69.1.85

James, L. R., \& Jones, A. P. (1974). Organizational climate: A review of theory and research. Psychological bulletin, 81(12), 1096-1112. doi: 10.1037/h0037511

Kossinets, G. (2006). Effects of missing data in social networks. Social Networks, 28, 247-268. doi: 10.1016/j.socnet.2005.07.002

Krumpal, I. (2013). Determinants of social desirability bias in sensitive surveys: a literature review. Quality \& Quantity, 47(4), 2025-2047. doi: 10.1007/s11135-011-9640-9

Lazega, E., \& Snijders, T.A.B. (2016). Multilevel Network analysis for the Social Sciences. Cham, CH: Springer. doi: 10.1007/978-3-319-24520-1

Leithwood, K., Leonard, L., \& Sharratt, L. (1998). Conditions fostering organizational learning in schools. Educational Administration Quarterly, 34, 243-276. doi: 10.1177/0013161X98034002005 
Leonard, L. J. (2002). Schools as Professional Communities: Addressing the Collaborative Challenge. IEJLL: International Electronic Journal for Leadership in Learning, 6(17).

Lieberman, A. (1990). Schools as collaborative cultures: Creating the future now. Bristol, UK: The Falmer Press.

Lieberman, A. (1995). Practices that support teacher development: Transforming conceptions of professional learning. Phi Delta Kappan, 76, 591-596.

Little, J. W. (1982). Norms of collegiality and experimentation: Workplace conditions of school success. American Educational Research Journal, 19, 325-340. doi: 10.3102/00028312019003325

Lock, P., \& Crawford, J. (1999). The relationship between commitment and organizational culture, subculture, leadership style and job satisfaction in organizational change and development. Leadership and Organizational Development Journal, 20, 365-373. doi: 10.1108/01437739910302524

Louis, K. S., \& Kruse, S. D. (1995). Professionalism and community: Perspectives on reforming urban schools. Thousand Oaks, CA: SAGE Publications Ltd.

Louis, K. S., Marks, H. M., \& Kruse, S. (1996). Teachers' professional community in restructuring schools. American Educational Research Journal, 33, 757-798. doi: 10.3102/00028312033004757

Marks, H. M., \& Louis, K. S. (1997). Does teacher empowerment affect the classroom? The implications of teacher empowerment for instructional practice and student academic performance. Educational Evaluation and Policy Analysis, 19, 245-275. doi: 10.3102/01623737019003245

McFarland, D. A. (2001). Student resistance: How the formal and informal organization of classrooms facilitate everyday forms of student defiance. American Journal of Sociology, 107(3), 612-678. doi: $10.1086 / 338779$

McGraw, K. O., \& Wong, S. P. (1996). Forming inferences about some intraclass correlation coefficients. Psychological methods, 1(1), 30-46. doi: 10.1037/1082-989X.1.4.390

Moolenaar, N. M., Sleegers, P. J., \& Daly, A. J. (2012). Teaming up: Linking collaboration networks, collective efficacy, and student achievement. Teaching and Teacher Education, 28, 251-262. doi: 10.1016/j.tate.2011.10.001

Nias, J. (2005). Why teachers need their colleagues: A developmental perspective. In D. Hopkins (Ed.), The practice and theory of school improvement (pp. 223-237). Dordrecht, NL: Springer. doi: 10.1007/14020-4452-6

Payne, R. L., Fineman, S., \& Wall, T. D. (1976). Organizational climate and job satisfaction: A conceptual synthesis. Organizational behavior and human performance, 16(1), 45-62. doi: 10.1016/00305073(76)90006-4

Peterson, T. O., \& Beard, J. W. (2004). Workspace technology's impact on individual privacy and team interaction. Team Performance Management: An International Journal, 10(7/8), 163-172. doi: $10.1108 / 13527590410569887$

Raudenbush, S. W., \& Bryk, A. S. (2002). Hierarchical linear models: Applications and data analysis methods (Vol. 1). Thousand Oaks, CA: Sage.

Robins, G., \& Alexander, M. (2004). Small worlds among interlocking directors: Network structure and distance in bipartite graphs. Computational \& Mathematical Organization Theory, 10(1), 69-94. doi: 10.1023/B:CMOT.0000032580.12184.c0

Rubin, D. B., \& Little, R. J. (2002). Statistical analysis with missing data. New York, NY: John Wiley \& Sons.

Sackmann, S. A. (1992). Culture and subcultures: An analysis of organizational knowledge. Administrative science quarterly, 37(1), 140-161. doi: 10.2307/2393536

Schein, E. H. (1985). Defining organizational culture. Classics of organization theory, 3, 490-502.

Schein, E. H. (2010). Organizational culture and leadership (Vol. 2). San Francisco, CA: John Wiley \& Sons.

Schneider, B. (1975). Organizational climate: Individual preferences and organizational realities revisited. Journal of Applied Psychology, 60(4), 459-465. doi: 10.1037/h0076919

Scott, J. (1991) Social Network Analysis: a Handbook. London, UK: Sage. doi: 10.4135/9781446294413 
Siskin, L. S. (1991). Departments as different worlds: Subject subcultures in secondary schools. Educational Administration Quarterly, 27, 134-160. doi: 10.1177/0013161X91027002003

Soeters, J. (1988). Organisatiecultuur: Inhoud, betekenis en veranderbaarheid [Organizational culture: Content, meaning and changeability]. In J.J. Swanink (Ed.), Werken met organisatiecultuur: De harde gevolgen van de zachte factor [Working with organizational culture: The harsh effects of the soft factor] (pp. 15-27). Vlaardingen: Nederlands Studie Centrum.

Strahan, D. (2003). Promoting a collaborative professional culture in three elementary schools that have beaten the odds. The Elementary School Journal, 104(2), 127-146. doi: 10.1086/499746

Sveiby, K. E., \& Simons, R. (2002). Collaborative climate and effectiveness of knowledge work-an empirical study. Journal of Knowledge Management, 6, 420-433. doi: 10.1108/13673270210450388

Van Maanen, J., \& Schein, E. H. (1979). Towards a theory of organizational socialization. In B. M. Staw (Ed.), Research in organizational behavior, vol. 1 (pp. 209-264). Greenwich, CT: JAI Press.

Van Maele, D., Moolenaar, N.M., \& Daly, A.J. (2015). All for one and one for all: A social network perspective on the effects of social influence on teacher trust. In M. DiPaola \& W.K. Hoy (Eds.) (pp. 171-196), Leadership and School Quality. Greenwich, CT: Information Age Publishing.

Visscher, A., \& Witziers, B. (2004). Subject departments as professional communities? British Educational Research Journal, 30(6), 785-800. doi: 10.1080/0141192042000279503

Waldron, N. L., \& McLeskey, J. (2010). Establishing a collaborative school culture through comprehensive school reform. Journal of Educational and Psychological Consultation, 20(1), 58-74. doi: $10.1080 / 10474410903535364$

Wasserman, S., \& Faust, K. (1994). Social network analysis: Methods and applications (Vol. 8). Cambridge, UK: Cambridge university press. doi: 10.1017/CBO9780511815478

Wellman, B., \& Frank, K. (2001). Network capital in a multilevel world: Getting support from personal communities. In N. Lin, R.S. Burt \& K. Cook (Eds.), Social Capital: Theory and Research (pp. 233273), New York, NY: Aldine De Gruyter Hawthorne.

Yang, J. T. (2007). Knowledge sharing: Investigating appropriate leadership roles and collaborative culture. Tourism Management, 28, 530-543. doi: 10.1016/j.tourman.2006.08.006 